\title{
On Implicit Knowledge Learning Model in Multi-modal Listening Class
}

\author{
Xin Zuo ${ }^{1, a}$, Limin Wang ${ }^{2, b}$ \\ ${ }^{1}$ School of Foreign Languages, ChangChun University of Technology, ChangChun130012, China \\ ${ }^{2}$ College of Computer Science and Technology, JiLin University, Changchun 130012, China \\ avaleriazuo@126.com, bwanglim@jlu.edu.cn
}

\begin{abstract}
Higher education plays an important role in the implementation of quality education. And the quality education immersed in the respective subjects of higher education is the inevitable requirement of higher education to cultivate innovative talents with high quality. Moreover, implicit knowledge is the source of students' innovative ability. This study intends to investigate a new type of multi - modal English teaching method to teach the implicit knowledge. Based on the experimental data, it proves that as implicit knowledge is acquired, quality education and students' innovative ability can also be completed.
\end{abstract}

Keywords: quality education; implicit knowledge; multi-modal discourse; listening.

\section{多模态听力教学环境下隐性知识学习模式探究}

\section{左欣 ${ }^{1}$, 王利民 ${ }^{2}$}

1. 长春工业大学外国语学院, 长春 中国;

2. 吉林大学计算机科学与技术学院, 长春 中国

摘 要: 高等教育在实施素质教育中占有重要地位, 而将素质教育渗透在各门学科的教学中也 是高等教育培养高素质创新人才的必然要求, 而隐性知识是学生创新能力的源泉。本研究探 讨利用新型多模态英语教学法传授隐性知识的教学模式, 基于数据分析通过实验论证隐性知 识习得的同时, 完成了对学生的素质教育和创新能力的培养。

关键词: 素质教育; 隐性知识; 多模态话语; 听力.

\section{1. 前言}

相对于传统的应试教育, 为适应社会发展, 国家提出了素质教育把提高人才创新能力摆到了 关系民族复兴和国家兴旺的重要位置。国务院在 1999 年 6 月召开的改革开放以来第三次全国 教育工作会议上, 为使全面推进素质教育成为迎接新世纪教育工作的战略重点, 国务院发布 了《关于深化教育改革全面推进素质教育的决定》的纲领性文件。近年来, 随着世界经济的 不断发展和进步, 学好英语了解国外的先进文化增强世界意识, 已成为素质教育的关键组成 部分。在中共中央、国务院《关于进一步加强和改进大学生思想政治教育的意见》中明确规 定： “高等学校各门课程都具有育人功能, 所有教师都负有育人职责”。这说明, 将素质教 育渗透在各门学科中, 完善学生知识结构, 提高我国课堂教学质量和效率, 培养高素质人才 已是大势所趋。因此, 在高校实现素质教育, 已成为本科教学质量和教学改革的重要目标之 一。而英语学科具备进行素质教育的独特优势, 决定了它在素质教育中占有不可替代的作用。 改变传统的教学模式和旧的学习方法, 培养适应知识经济、信息社会需要的人才, 把素质教 育落到实处, 在各学科教学中全面推进素质教育是社会和时代发展对教育提出的客观要求。 


\section{2. 素质教育的内涵}

素质是指人们先天具有和后天习得的一系列特点和品质的综合, 它有狭义和广义之分, 狭义 的素质, 即先天遗传素质, 是指生理学和心理学意义上的概念; 广义的素质是指后天习得的 素质, 是教育学意义上的概念, 即素质教育中的 “素质”。一般认为, 人的素质由自然素质、 心理素质和社会素质三大部分构成。人的素质通过环境和教育的影响, 依靠人类内化社会发 展的物质文明和精神文明成果, 将其积淀于个体身上, 从而形成稳定而巩固的生理和心理方 面的属性。

素质教育是一个综合性的概念, 强调培养人的全面素质（整体性）, 又强调面向全体学生（全 体性）, 充分重视学生的主体地位, 开发学生的智慧, 实质是以提高受教育者诸多方面素质 为目标的一种教育模式, 并强调受教育者具备在社会实践中不断提高自身修养的基本品质。 素质教育以人为本, 在提高生理素质的基础上, 培养学生学会学习、学会做人和学会发展, 以提高全民族素质为宗旨和根本目的。素质教育的结果, 在个体很长时间甚至是整个生命过 程中逐渐反映出来的综合特征, 其很多方面都不能用具体的量化评价办法和体系指标来度量。 但作为现代教育体系核心力量的高等教育, 必须承担起全面培养, 完善和提高大学生智能和 品德素质的素质教育使命, 并在素质教育中起到主要作用。作为一种技能培养和文化传播的 英语教学, 属于实施素质教育的一部分, 它自身的英语教学理论为素质教育的实施创造了条 件, 提供了方法和途径。

\section{3. 素质教育实施的方法与途径}

\section{1 在多模态教学环境下实施素质教育}

在多模态教学环境中推行素质教育可以促进学生智力的发展, 启发学生的思维。模态是指通 过人类感官系统如视觉、听觉等, 与外部环境如人、机器、物件等进行的互动方式, 它以媒 体为物质基础的。没有媒体, 模态就不能发挥其具体作用, 抽象的模态必须以媒体为媒介。 媒体是符号分布印迹的物质手段, 是所有符号系统的载体及表达媒介, 是模态借助其从抽象 转化为具体的载体。多模态话语指人类通过多种符号资源和表意手段 (如语言、图像、声音、 动作等), 及运用听觉、视觉、触觉等多种感觉器官, 进行交际的现象, 从严格意义上说, 现 实中 “所有的交流都是多模态的”。传统教学方法忽略了声音、图像、颜色等其他模态的非 语言因素在学生掌握知识过程中, 扮演的重要角色。心理学家赤瑞特拉的实验研究结果表明, 人的听觉模态使人注意力集中达到的比率仅为 $54.6 \%$, 而视觉模态能达到 $81.7 \%$ 。在课堂教学 中采用多模态教学手段有助于激发学生的学习兴趣, 使他们更容易了解西方文化知识, 增强 学生全面素质。

因此, 在英语教学中必须将素质教育融于课堂多模态话语中。Halliday把语言看做一个表义 系统或一个社会符号系统。除语言外, 还有绘画、雕刻、音乐、舞蹈等表义系统, 它们与语 言共同实现社会意义。它为系统功能语言学的社会符号学理论奠定了基础, 也为多模态话语 分析理论发展提供理论依据。口语语言符号是英语课堂主要交流方式, 也是进行素质教育的 主要途径。主要包括教师口头讲授和提问时的语言符号、学生互动时的语言符号以及音频材 料播放时的语言符号。人与环境相互关系和相互影响的规律是环境科学研究的对象之一。教 学环境由于包括各种较为复杂的因素, 成为一种较为特殊的社会环境。人类调节行为, 最大 限度地达到目标, 而不是通过适应环境来满足自己的欲望并达到自己的目标。课堂上多模态 教学环境的采用更能满足学生的求知欲, 通过教师的话语和多种模态教学环境了解知识, 帮 助学生吸收课堂教学内容, 完善知识体系, 增强自身素质。

教师还应有意识地运用多种教学模态来引导学生作为主体, 课堂活动也尽量与生活贴近, 鼓 励学生结合语言和非语言形式表达观点, 增强自信心和口语表达能力, 全面进行素质教育培 养。多模态学习模式, 包含了视觉、听觉、触觉等多种模态作用于接受体学生, 接受的信息 在学生大脑中分别转换成短时视觉记忆、听觉记忆和触觉记忆。学生认知主体获取信息后形 
成短时记忆, 再经过感知、重组、编码便可转换并储存在长时记忆里。这样的有序循环有助 于学生知识的习得和记忆水平的提高, 同时完善他们的认知能力系统。培养和训练了学生思 想意义的表达能力, 也有利于学生有意识地、自动化地产出口头或者书面的语言学习结果。 整个输入到输出的过程符合人类认识获取知识、及行为能力养成和培养的特点。因此从认知 心理学角度看, 通过多模态话语进行教学有助于学生全面素质的提升。

\section{2 在隐性知识教学中实现素质教育}

21 世纪是知识创新、知识传播、知识更新的时代, 面对激烈的国际竞争, 国内外市场对人才 提出更高更强的全面发展要求。素质教育与人的隐性知识具有紧密的联系。人的全面素质本 身就存在于人的潜意识中, 它由隐性知识和显性知识构成。显性知识可以定义为可陈述的关 于规则的知识, 是可以明确清楚的表达, 具有正式的和系统化的特征; 而隐性知识是个人的 沉默潜在的直觉性知识, 它根植于人的行为和经验之中, 具有难以清楚表述且难以传递的特 点。它是显性知识的源泉, 难以用语言、文字、图像表达, 但支撑、凸现着人们能意识到的 显性知识, 可以说人类往往借助隐蔽的隐性知识力量支配自己的显性知识。

注重建构多元复合型人才, 具有深远意义。隐性知识是学生拥有创造力的原动力, 是实现素 质教育的一个重要方面, 也是高等教育教学改革的重要组成部分。素质教育强调开发人的潜 能, 培养人的全面能力, 丰富健全人的知识结构。学生在课堂上获取的显性知识已很难适应 当今的社会需要, 而课堂教学过程中往往隐藏着大量积极正面的隐性知识, 帮助学生生成、 获得和转化隐性知识就显得尤为重要。

因此, 在课堂教学实践中, 改变传统的知识传授型教学模式, 采用基于计算机等多媒体辅助 教学, 向素质教育教学模式转变已成为必然。整个教学过程中, 教师有意识的借助多种模态, 将自己的隐性知识显性化并传递给学生, 学生借助多模态进行理解和学习, 将教师传递的显 性知识消化和吸收, 通过大脑加工处理, 将其转化成自我的隐性知识, 并与原有知识网相衔 接, 学生在课堂上的反馈也丰富完善教师的隐性知识, 使课堂教学形成一个在多模态教学环 境下, 隐性知识动态流动和传递的过程, 实现对知识的超越, 进而达到培养学生素质教育的 目标。而当前的大学英语课堂, 在传统单一模态的教学环境下, 隐性知识未受到积极关注, 其利用和转化也被忽视。因此, 利用多模态有效地实现隐性知识的挖掘、转化和共享, 有助 于本科教学改革, 提高课堂教学质量, 增强课堂教学效果, 实现素质教育。以下研究探讨采 用多模态教学法传授隐性知识的新型教学模式, 基于数据分析通过实验论证隐性知识习得的 同时, 完成了对学生的素质教育。

\section{4. 素质教育在大学英语教学中的实证分析}

\section{1 受试者}

本研究的受试为某大学非英语专业2009 级共 116 名大一学生, 在入学后的大学英语分级教学 考试中, 他们分别考入两个A班 (英语成绩优秀者进入 $A$ 班, 每班人数均为 58 人) 。在英语听 力上, 一个班为实验组, 选取的听力教材是《走遍美国》 (Family Album, U. S. A. ) 的多媒 体版; 另一个班为对照组, 使用的教材是 $\mathrm{CD}$ 版。

\section{2 实验简介}

两个班在听力课和精读课上均采取一样的教学手段和教学方法。唯一的区别在于一个班的学 生使用多媒体, 在听力的过程中配备视频, 另一个班只使用录音机。《走遍美国》共26集, 每集三幕, 每次课学习两幕, 整个研究跟踪三学期; 第四学期听力课上, 为帮助学生通过四 级, 两组学生均主要练习历年四级听力真题。实验步骤如下: 1) 在大学英语第一节听力上对 116名学生进行听力测试, 分别计算出两个班的平均成绩和方差; 同时要求学生回答影响听力 能力提高的因素问卷 (包括语言知识, 文化背景, 听力策略等方面); 2) 统计这些学生在前 三个学期期末考试中的听力成绩, 并计算出两个班的平均成绩和方差；3）在第四学期期末, 要求学生回答影响听力能力提高因素的问卷 (等同第一步)；4）统计这些学生在四级考试中 的听力成绩, 计算出两个班的平均成绩和方差。 


\section{3. 实验结果与数据分析}

经过两年的大学英语听力学习, 两组学生在听力能力上, 由最初的水平相当发展到有明显差 距, 并影响到四级通过的总成绩。在对照组的课堂上, 学生获取的显性知识并不能有效的激 发学生的学习兴趣, 而现在多媒体教学条件为显性知识向隐性知识转化提供了前提条件。可 见, 多模态教学激发了学生的学习兴趣, 提高了课堂效率。多模态教学很好地体现了E11is 的弱接口说理论, 显性知识和隐性知识是一个连续体, 在一定条件下, 显性知识可以向隐性 知识转化。由于隐性知识形式的多样性、内容的未编码性、流动的即时性与依附性等特征造 成话语和文字表达的隐性知识转移的困难性, 但用视觉模态中的角色建模语言来构建学习行 为模型, 实现知识的建构和学生的主体地位的确立, 有助于学生理解听力材料。又通过口语 交际练习生词引起学生的兴趣, 设定语境信息使人文知识可以完全被理解, 熟练掌握后使学 生能有力地再现文化内涵。因此通过多模态的语言分析方法, 利用文字表达意义的做法与视 觉、听觉、手势等其他表意方式相结合, 最终形成存在于学生大脑中的英语语音知识、语法 知识、词汇知识、文化背景等隐性知识。 表1受试两个班的平均成绩和方差对比

\begin{tabular}{|c|c|c|c|}
\hline 成绩 & 对照班 & 实验班 \\
\hline \multirow{2}{*}{ 第一节听力课 } & 平均值 & 75 & 75 \\
\cline { 2 - 4 } & 方差 & 1.7 & 1.6 \\
\hline \multirow{2}{*}{ 第一学期期末 } & 平均值 & 75 & 78 \\
\cline { 2 - 4 } & 方差 & 1.9 & 77 \\
\hline \multirow{2}{*}{ 第二学期期末 } & 平均值 & 73 & 1.5 \\
\cline { 2 - 4 } & 方差 & 2.1 & 78 \\
\hline \multirow{2}{*}{ 第三学期期末 } & 平均值 & 72 & 1.2 \\
\cline { 2 - 4 } & 方差 & 2.3 & 25 \\
\hline \multirow{2}{*}{ 四级考试 } & 平均值 & 20 & 1.3 \\
\cline { 2 - 4 } & 方差 & 2.6 & . \\
\cline { 2 - 4 } & &
\end{tabular}

在实验组的课堂上, 教师从多模态话语视角出发, 利用多种手段和符号资源, 运用显性知识 产生输出, 输出的内容又作为自动的输入提供给隐性学习机制, 有效地实现不同符号在第二 语言课堂教学中多模态的协同性等, 完成认知任务过程的隐性知识的习得和知识的相互渗透, 表现为多元的互动关系。在学习过程中, 教师和学生可以利用多种模态, 结合认知心理学有 效地实现隐性知识的挖掘、转化和共享, 在认知过程中丰富学生的文化背景知识, 鼓励学生 大胆发言, 用于发表自己的见解, 把自己的探索、发现过程用语言表达出来, 培养语言思维 和语言表达能力, 增强学生自信心。在使实验组学生直观地感受到多模态系统的同时, 学生 也能积极主动地参与到教学过程, 如身临其境的感受西方文化和了解风土人情。语言教学不 是简单的单词和语法层面的知识传授, 在课堂上评价过程中教师采用了个人陈述、小组讨论 或辩论等多种形式。教师帮助学生设计应用于不同语境的语言表达形式, 生成新的意义, 潜 移默化地形成具有深远作用的隐性知识。他们不再是知识的被动接受者, 而是主动、积极的 知识探索者和建构者, 自身素质得到全面提升, 实现了在英语学科教育中, 对学生进行素质 教育的任务。

\section{References}

[1]. Gonzaley-Loret, M. Designing task-based CALL to pro-mote interaction: Enbuscade Esmeraldas[J]. Language Learning \& Technology, Vol. 7 (2003) p. 88-92.

[2]. Kress, G. \& van Leeuwen, T. Multimodal Discourse: The Mode and Media of Contemporary Communication [M]. London: Arnold, 2001, 21-22.

[3]. O’ Halloran, Kay L.(ed.). Multimodal Discourse Analysis: Systemic Functional Perspectives [M]. London: Continuum, 2004, 25-35. 